\title{
Sistem Monitoring Energi Lampu Penerangan Jalan Umum Berbasis Wireless Sensor Network dengan Topologi Mesh
}

\author{
Rudy Santoso Lukito',Deddy Susilo²,F. Dalu Setiaji ${ }^{3}$ \\ Program Studi Teknik Elektro, \\ Fakultas Teknik Elektronika dan Komputer \\ Universitas Kristen Satya Wacana, Salatiga \\ 1612011047@student.uksw.edu, ${ }^{2}$ deddy.susilo@staff.uksw.edu, ${ }^{3}$ dalu.setiaji@staff.uksw.edu,
}

\begin{abstract}
Ringkasan
Pada makalah ini dibuat suatu sistem untuk memantau energi listrik yang terpakai pada lampu penerangan jalan umum dan mengirimkan datanya, berbasis wireless sensor network dengan topologi mesh. Terdapat modul slave yang dipasang pada tiang lampu jalan yang terdiri dari sensor tegangan jala-jala PLN, sensor arus yang terpakai oleh lampu, dan sensor intensitas cahaya yang dihasilkan lampu. Mikrokontroler Arduino pro mini 3,3V $8 \mathrm{MHz}$ digunakan untuk mengolah data dari sensor sehingga dapat diketahui besarnya daya yang digunakan oleh lampu. Wireless sensor network dengan topologi mesh dirancang untuk untuk mengatasi gagalnya pengiriman data dari modul slave ke modul master di komputer server. Wireless sensor network dirancang menggunakan RF transceiver. Hasil pengujian menunjukkan sensor tegangan, arus dan intensitas cahaya memiliki ralat di bawah $3 \%$. Perancangan wireless sensor network dengan topologi mesh berhasil direalisasikan, dimana ketika salah satu modul slave yang tidak berfungsi, semua data dari modul slave yang berfungsi tetap dapat diterima oleh modul master.
\end{abstract}

Kata kunci: Sistem monitoring, wireless sensor network, slave, master, topologi mesh.

\section{Pendahuluan}

Energi listrik yang sangat berharga, banyak digunakan untuk lampu penerangan jalan umum dalam jumlah banyak. Untuk satu buah lampu jalan, konsumsi daya yang dibutuhkan cukup besar yaitu antara $18 \mathrm{~W}$ sampai 700W. Namun sering terlihat bahwa lampu jalan belum mati saat siang hari, sehingga memboroskan energi listrik. Belum lagi jika lampu sudah mulai menurun kualitasnya sehingga intensitas cahayanya menjadi tidak maksimal.

Maka dari itu, dirancang sebuah sistem pemantau energi listrik yang digunakan lampu jalan dengan pengiriman data berbasis wireless sensor network bertopologi mesh. Data tersebut nantinya diharapkan dapat digunakan untuk mengambil langkah yang tepat jika terjadi masalah pada lampu jalan, yang tujuan utamanya adalah menghemat pemakaian energi listrik. Penggunaan wireless sensor network dengan topologi mesh dirancang menggunakan modul RF transceiver NRF24L01 0dBm yang hemat daya, tidak memerlukan biaya dalam pengiriman datanya dan dapat digunakan untuk pengiriman data jarak jauh. 


\section{Kajian Pustaka}

Sejumlah sistem dengan tujuan sejenis telah dikembangkan dengan menggunakan berbagai macam cara pengiriman data dan penerapannya. Pada bab ini akan dibahas beberapa di antaranya sebagai bahan acuan dan perbandingan.

\subsection{Desain Sistem Monitoring dan Kontrol Penggunaan Energi Listrik Menggunakan Wireless Sensor Network [1]}

Sistem monitoring energi listrik digunakan untuk mendeteksi penggunaan energi listrik yang dipakai oleh beban. Dalam sistem monitoring ini dilakukan pengukuran besaran arus listrik menggunakan sensor arus. Pengukuran arus listrik dilakukan pada beberapa titik beban yang telah dimodifikasi dengan penambahan pemancar dan sebuah modul penerima pada server yang digunakan untuk menerima dan mengolah data hasil pengamatan. Desain sistem ini menggunakan teknologi Wireless Sensor Network (WSN), dengan transmisi data menggunakan standar protokol IEEE 802.15.4/zigbee. Dari pengujian sistem didapatkan jarak jangkau transmisi data maksimal dalam kondisi Line of Sight (LOS) adalah 100 meter, sedangkan pada kondisi Non Line of Sight (NLOS) sejauh 35 meter, dengan penghalang berupa tembok beton setebal $15 \mathrm{~cm}$.

\subsection{Implementasi Wireless Sensor Network untuk Monitoring Parameter Energi Listrik sebagai Peningkatan Layanan Bagi Penyedia Energi Listrik [2]}

Pada acuan ini, parameter energi listrik yang dimonitor adalah tegangan, arus, frekuensi dan beda phase. Data parameter energi listrik pada setiap sensor dikirimkan secara nirkabel menggunakan modul RF ke gateway. Sisi gateway akan terkoneksi GPRS menggunakan modem GPRS dan mengirim paket-paket data ke web database. Konsumen dapat mengakses data-data tersebut melalui telepon genggam. Pada web tersebut akan ditampilkan data-data energi listrik sesuai waktu dan wilayah yang ingin ditampilkan, untuk menginformasikan penggunaan energi listrik yang dikonsumsi. Modul RF yang digunakan dapat mengirimkan data sejauh 300 meter.

Perbedaan sistem yang dibuat dibandingkan dua pustaka di atas adalah, pada sistem ini pengiriman dan penerimaan data dilakukan menggunakan modul transceiver umum yang memiliki frekuensi kerja $2,4 \mathrm{GHz}$ dan menanamkan protokol Wireless Sensor Network secara software. Juga terdapat kendali terpusat untuk mengaktifkan dan menonaktifkan lampu jalan secara paksa (force control) untuk keperluan maintenance rutin dan hal-hal khusus dari pusat kendali. Terdapatnya sensor pengukur intensitas cahaya lampu jalan dapat mendukung keperluan maintenance rutin lampu jalan yang rusak atau mati.

\section{Perancangan dan Penerapan}

\subsection{Sistem Kontrol}

Sistem kontrol yang dirancang menggunakan mikrokontroler Arduino pro mini 3,3 V $8 \mathrm{MHz}$ sebagai pengendali utama. Terdapat lima modul slave terpasang pada tiang lampu jalan dan 1 modul master pada komputer server. Tiap modul slave terdiri sensor arus, sensor tegangan, sensor cahaya dan NRF24L01. Gambar 1 menunjukkan blok diagram modul slave. 


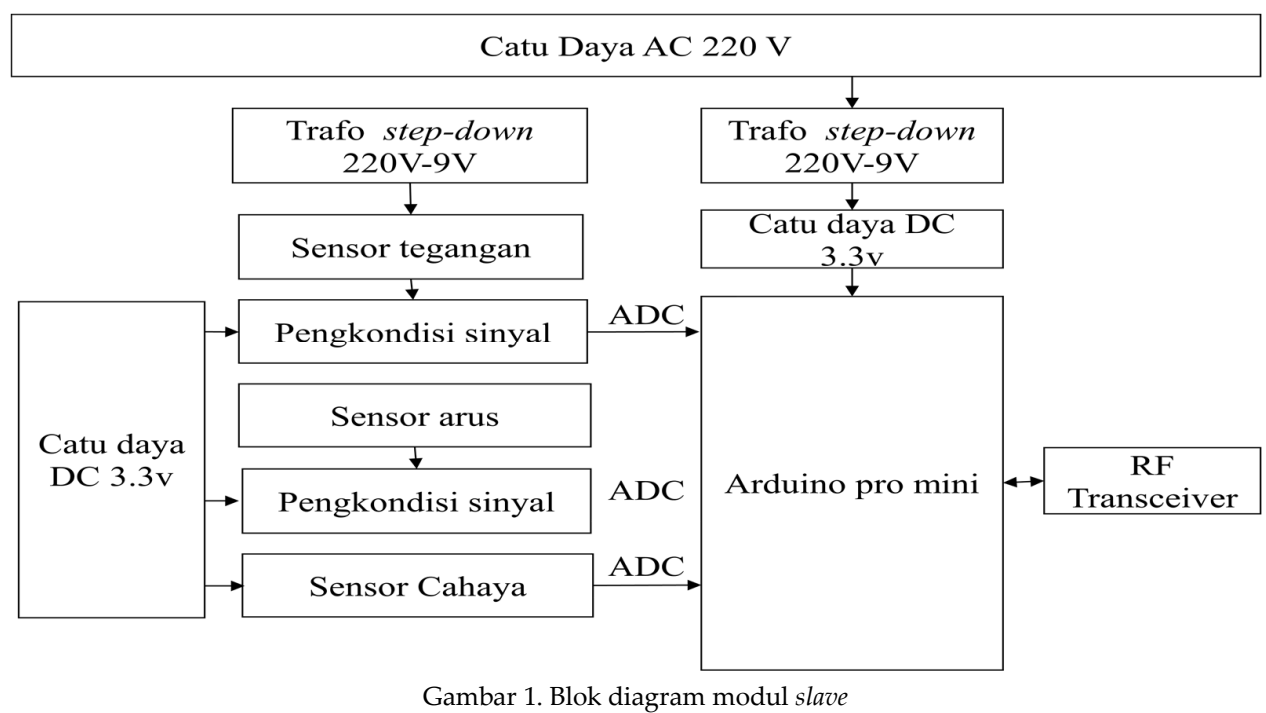

Sensor tegangan digunakan untuk mengukur tegangan rms jala-jala, sensor arus noninvasive YHDC SCT-020 digunakan untuk mengukur arus rms, dan sensor cahaya BH1750 untuk mengukur intensitas cahaya cahaya lampu jalan. Pengkondisi sinyal dirancang agar tegangan yang keluar dari sensor dapat sesuai dengan jangkauan tegangan masukan pin ADC arduino. Modul master sebagai penerima data terdiri dari NRF24101. Gambar 2 menunjukkan blok diagram modul master.

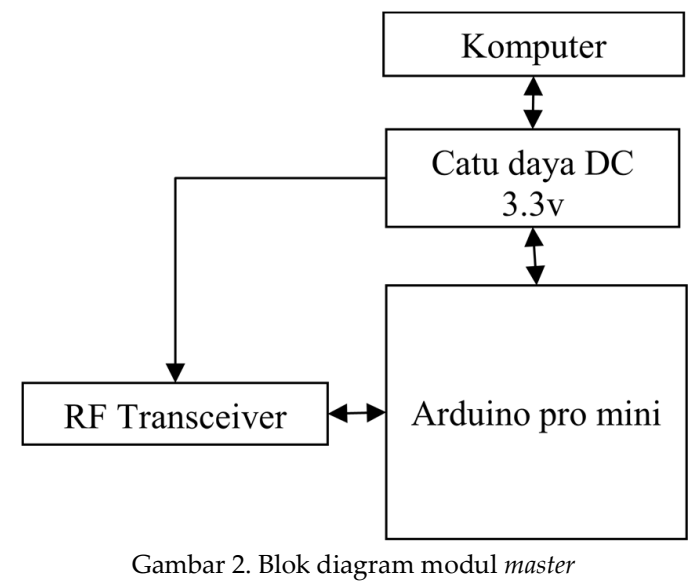

\subsection{Perangkat Keras Sistem}

Perangkat keras modul slave yang direalisasikan dalam penelitian ini memiliki ukuran pnampang $11 \mathrm{~cm} \times 8,6 \mathrm{~cm}$ yang dapat mudah ditempelkan pada tiang lampu jalan seperti ditunjukkan Gambar 3. 


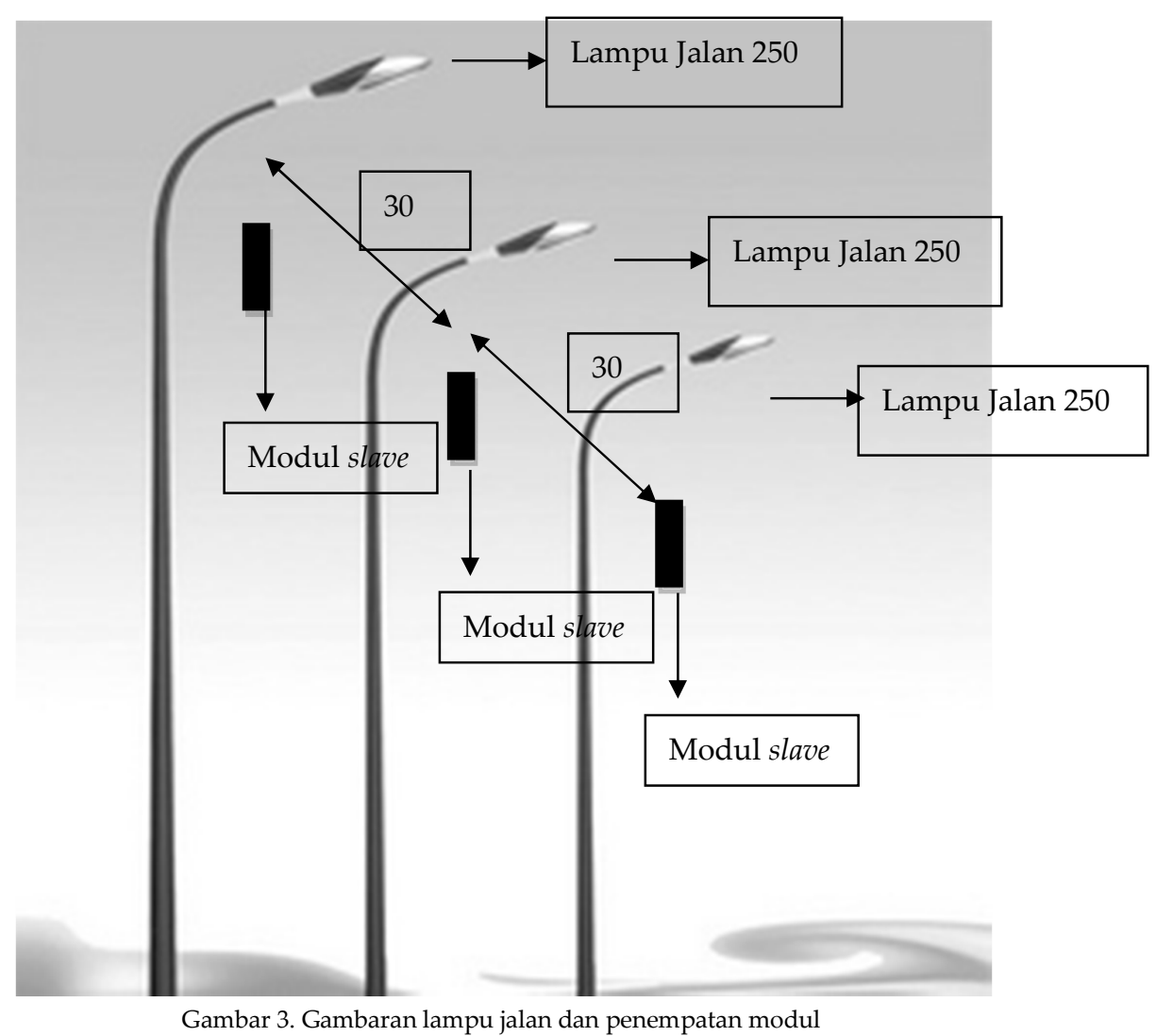

\subsection{Perangkat Lunak Sistem}

Perancangan perangkat lunak yang akan dijelaskan dibagi menjadi tiga bagian yaitu perancangan perangkat lunak modul slave, modul master, dan komputer server. Gambar 4 menunjukkan diagram alir modul master yang bertugas menerima data dari modul slave dan dikirimkan ke komputer server secara serial.

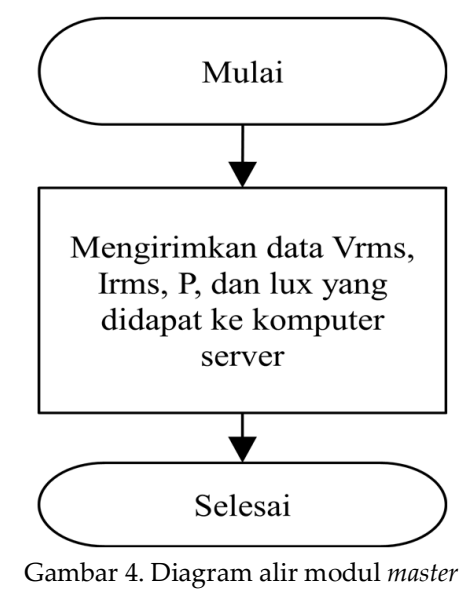

Pada komputer server, digunakan aplikasi Microsoft Visual Studio 2010 untuk menampilkan data yang dikirmkan modul master dan melakukan perhitungan daya nyata (S), daya reaktif (Q), faktor daya (pf), dan jumlah energi (dalam kWh). Microsoft 
Sistem Monitoring Energi Lampu Penerangan Jalan Umum Berbasis Wireless Sensor Network dengan Topologi Mesh

Rudy Santoso Lukito,Deddy Susilo,F. Dalu Setiaji

Access 2010 digunakan sebagai database. Gambar 5 menunjukkan diagram alir komputer server.

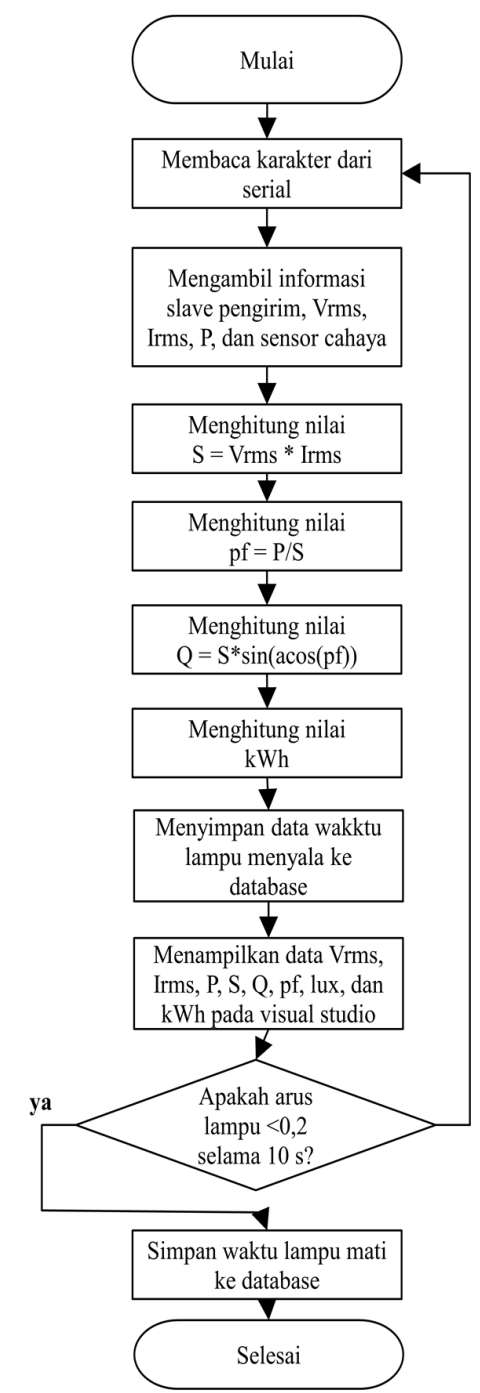

Gambar 5. diagram alir komputer server.

Pada modul slave, data yang diambil berupa tegangan rms, arus rms, intensitas cahaya, dan melakukan perhitungan daya aktif. Gambar 6 menunjukkan diagram alir modul slave. 
Techné Jurnal Ilmiah Elektroteknika Vol. 15 No. 1 April 2016 Hal 39 - 46

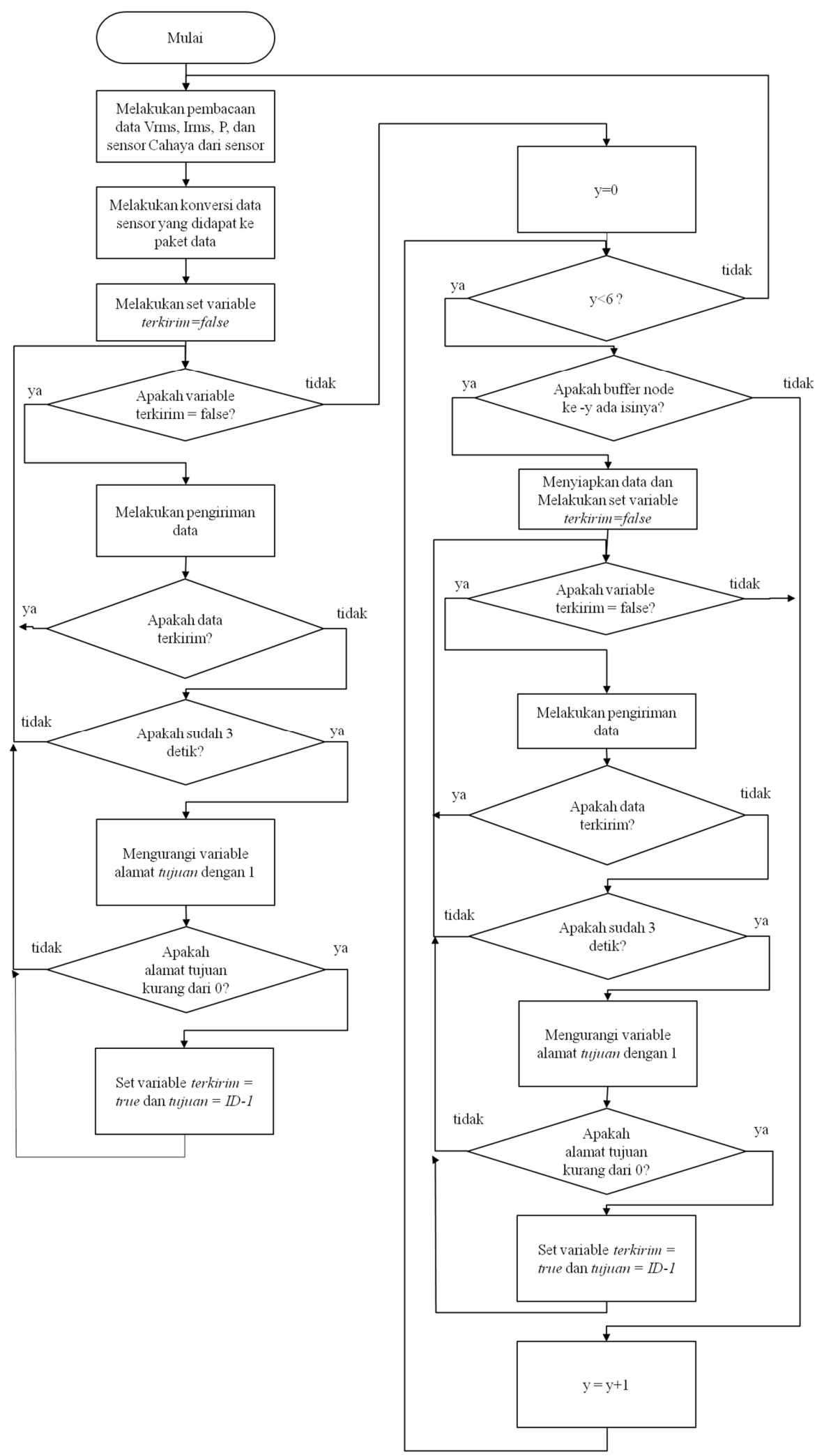

Gambar 6. diagram alir modul slave. 


\section{Pengujian dan Pembahasan}

Pengujian dilakukan dengan mengambil 10 data pembacaan tegangan dan arus menggunakan multimeter dan hasil perhitungan daya nyatanya, kemudian dibandingkan dengan hasil pembacaan alat yang dibuat. Beban yang digunakan yaitu lampu jalan $250 \mathrm{~W}$. Tabel 1 menunjukkan hasil pengujian tersebut. Pengujian dilanjutkan dengan menguji sensor cahaya seperti ditunjukkan Tabel 2.

Tabel 1. Hasil pengujian tegangan RMS, arus RMS, dan daya nyata

\begin{tabular}{|c|c|c|c|c|c|c|c|c|c|}
\hline Data & $\begin{array}{c}\text { Vrms } \\
\text { Multi(V) }\end{array}$ & $\begin{array}{c}\text { Vrms } \\
\text { Alat(V) }\end{array}$ & $\begin{array}{c}\text { Ralat } \\
(\%)\end{array}$ & $\begin{array}{c}\text { Irms } \\
\text { Multi(A) }\end{array}$ & $\begin{array}{c}\text { Irms } \\
\text { Alat(A) }\end{array}$ & $\begin{array}{c}\text { Ralat } \\
(\%)\end{array}$ & $\begin{array}{c}\text { Daya } \\
\text { Nyata(VA) }\end{array}$ & $\begin{array}{c}\text { Daya } \\
\text { Nyata } \\
\text { Alat(VA) }\end{array}$ & $\begin{array}{c}\text { Ralat } \\
(\%)\end{array}$ \\
\hline 1 & 224,5 & 224,07 & 0,0019 & 1,864 & 1,86 & 0,0021 & 418,46 & 416,77 & 0,4 \\
\hline 2 & 224,2 & 223,67 & 0,0023 & 1,864 & 1,86 & 0,0021 & 417,9 & 416,02 & 0,44 \\
\hline 3 & 224,5 & 223,38 & 0,0049 & 1,864 & 1,86 & 0,0021 & 418,46 & 415,48 & 0,71 \\
\hline 4 & 224,7 & 224,3 & 0,0017 & 1,863 & 1,86 & 0,0016 & 418,61 & 417,19 & 0,33 \\
\hline 5 & 224,5 & 224,19 & 0,0013 & 1,863 & 1,86 & 0,0016 & 418,24 & 416,99 & 0,29 \\
\hline 6 & 224,6 & 224,22 & 0,0016 & 1,862 & 1,86 & 0,001 & 418,2 & 417,04 & 0,27 \\
\hline 7 & 224,1 & 223,84 & 0,0011 & 1,862 & 1,86 & 0,001 & 417,27 & 416,34 & 0,22 \\
\hline 8 & 224,9 & 224,56 & 0,0015 & 1,862 & 1,86 & 0,001 & 418,76 & 417,68 & 0,25 \\
\hline 9 & 225,5 & 225,04 & 0,002 & 1,861 & 1,86 & 0,0005 & 419,65 & 418,57 & 0,25 \\
\hline 10 & 225,5 & 225,03 & 0,002 & 1,861 & 1,86 & 0,0005 & 419,65 & 418,55 & 0,26 \\
\hline $\begin{array}{l}\text { Rata- } \\
\text { rata }\end{array}$ & 224,7 & 224,23 & $\mathbf{0 , 0 0 2}$ & $\mathbf{1 , 8 6}$ & $\mathbf{1 , 8 6}$ & $\mathbf{0 , 0 0 1 3}$ & 418,52 & 417,06 & $\mathbf{0 , 3 4}$ \\
\hline
\end{tabular}

Tabel 2. Hasil pengujian sensor cahaya

\begin{tabular}{|c|c|c|c|}
\hline Data ke & $\begin{array}{c}\text { Lux Meter } \\
(\text { lux })\end{array}$ & $\begin{array}{c}\text { Sensor Cahaya } \\
(\text { lux })\end{array}$ & Ralat(\%) \\
\hline 1 & 5180 & 5236 & 1,08 \\
\hline 2 & 5170 & 5123 & 0,9 \\
\hline 3 & 5180 & 5024 & 3,01 \\
\hline 4 & 5160 & 5132 & 0,54 \\
\hline 5 & 5170 & 5234 & 1,23 \\
\hline 6 & 5170 & 5135 & 0,67 \\
\hline 7 & 5170 & 5022 & 2,86 \\
\hline 8 & 5180 & 5113 & 1,29 \\
\hline 9 & 5170 & 5230 & 1,16 \\
\hline 10 & 5180 & 5154 & 0,5 \\
\hline 11 & 5160 & 5024 & 2,63 \\
\hline 12 & 5150 & 5091 & 1,14 \\
\hline 13 & 5160 & 5222 & 1,2 \\
\hline 14 & 5180 & 5172 & 0,15 \\
\hline 15 & 5100 & 5031 & 1,35 \\
\hline
\end{tabular}

Pengujian dilakukan dengan membandingkan pembacaan nilai lux lampu jalan oleh sensor cahaya yang digunakan dengan alat LUX Meter TES 1330. Cara pengujian yaitu dengan meletakkan lux meter dan sensor cahaya bersebelahan dan sejajar. Lampu jalan berjarak $85 \mathrm{~cm}$ dari sensor cahaya dan lux meter Dengan mengacu pada pembacaan LUX Meter maka hasil pengujian sensor cahaya memiliki ralat maksimum $3 \%$. 
Pengujian wireless sensor network dilakukan untuk menguji kemampuan dari topologi mesh dalam mengirimkan data ke modul master walaupun ada modul slave yang mati. Pengujian dilakukan sebanyak 10 kali dengan melihat data yang masuk ke modul master ketika salah satu modul slave 1. Hasilnya ditunjukkan pada Tabel 3, yaitu semua data dapat terkirim dengan baik.

Tabel 3. Pengujian wireless sensor network ketika modul slave 1 mati

\begin{tabular}{|c|c|c|c|c|}
\hline \multirow{2}{*}{$\begin{array}{c}\text { Pengujian } \\
\text { ke }\end{array}$} & \multicolumn{4}{|c|}{ data dari slave } \\
\cline { 2 - 5 } & 2 & 3 & 4 & 5 \\
\hline 1 & $\mathrm{~V}$ & $\mathrm{~V}$ & $\mathrm{~V}$ & $\mathrm{~V}$ \\
\hline 2 & $\mathrm{~V}$ & $\mathrm{~V}$ & $\mathrm{~V}$ & $\mathrm{~V}$ \\
\hline 3 & $\mathrm{~V}$ & $\mathrm{~V}$ & $\mathrm{~V}$ & $\mathrm{~V}$ \\
\hline 4 & $\mathrm{~V}$ & $\mathrm{~V}$ & $\mathrm{~V}$ & $\mathrm{~V}$ \\
\hline 5 & $\mathrm{~V}$ & $\mathrm{~V}$ & $\mathrm{~V}$ & $\mathrm{~V}$ \\
\hline 6 & $\mathrm{~V}$ & $\mathrm{~V}$ & $\mathrm{~V}$ & $\mathrm{~V}$ \\
\hline 7 & $\mathrm{~V}$ & $\mathrm{~V}$ & $\mathrm{~V}$ & $\mathrm{~V}$ \\
\hline 8 & $\mathrm{~V}$ & $\mathrm{~V}$ & $\mathrm{~V}$ & $\mathrm{~V}$ \\
\hline 9 & $\mathrm{~V}$ & $\mathrm{~V}$ & $\mathrm{~V}$ & $\mathrm{~V}$ \\
\hline 10 & $\mathrm{~V}$ & $\mathrm{~V}$ & $\mathrm{~V}$ & $\mathrm{~V}$ \\
\hline
\end{tabular}

Tanda centang (V) pada Tabel 3 menunjukkan data yang berhasil diterima dengan baik oleh modul master. Dilakukan juga pengujian untuk mematikan lampu jalan dari modul master yang berhasil dengan baik.

\section{Kesimpulan}

Berdasarkan perancangan, perealisasian dan pengujian dapat ditarik kesimpulan sebagai berikut:

1. Alat dapat mengukur nilai tegangan jala-jala dengan ralat maksimal sebesar $0,005 \%$.

2. Alat dapat mengukur nilai arus beban dengan ralat maksimal sebesar $0,0021 \%$.

3. Alat dapat mengukur nilai daya nyata beban dengan ralat maksimal sebesar $0,71 \%$.

4. Alat dapat mengukur nilai intensitas cahaya lampu dengan ralat maksimal sebesar 3\%.

5. Dengan menerapkan Wireless Sensor Network bertopologi mesh, ketika ada satu modul slave mati maka data dari empat modul slave lainnya tetap dapat terkirim dengan baik ke modul master.

\section{Daftar Pustaka}

[1] Sirojuddin, Muhammad dkk, 2014 ,"Desain Sistem Monitoring dan Kontrol Penggunaan Energi Listrik Menggunakan WIreless Sensor Network", Salatiga:FSM UKSW

[2] Arrosyid, Moch Harun dkk, 2009, "Implementasi Wireless Sensor Network Untuk Monitoring Parameter Energi Listrik Sebagai Peningkatan Layanan Bagi Penyedia Energi Listrik", Surabaya:PENS ITS 